\title{
Analysis of the development in the Russian Arctic zone
}

\author{
N. Didenko ${ }^{1}$, K. Kunze ${ }^{2} \&$ D. Skripnuk ${ }^{1}$ \\ ${ }^{1}$ St. Petersburg State Polytechnical University, Russia \\ ${ }^{2}$ University of Colorado Denver, USA
}

\begin{abstract}
The socio-economic development of the Russian Arctic region includes the following areas of human activity: the social infrastructure, the institutional sector, the human development, the industrial sector and the ecology. The indicators evaluating each of these areas are characterized in the paper. The interdependence of human activities in the region is reflected in the regional socio-economic development model. In the regional socio-economic development model that is presented in the paper each area is characterized with indicators that can be endogenous and exogenous within the model. The socioeconomic development model is a system of six econometric equations, whereas each of them is an ADL-model. Each ADL-model includes endogenous and exogenous variables. The paper presents the structural form of the system of six econometric equations, where one of them includes more than one endogenous variable. The transition to the reduced form of the system of six econometric equations was shown. Each equation here includes only one endogenous variable, i.e. endogenous variables are expressed through the exogenous ones. The system of six econometric equations was worked out for Nenetsk region of Russia. The statistical data was obtained from the Russian State Statistic Committee database. The solution for the system of six econometric equations is represented in the paper.

Keywords: Russian Arctic region, socio-economic development, ADL-model, system of econometric equations.
\end{abstract}

\section{Introduction}

The paper analyzes the model of sustainable development of the Nenetsk region of Russia. Nenetsk region is the most sparsely populated out of 85 regions of 
Russia. According to Rosstat in 2014 [1, 2], it had only 43,000 people. Nenetsk region is located in the north of the East European Plain, a large part of the region is located above the Arctic Circle. In the Nenetsk region, there is only one major town, Naryan-Mar, and 42 rural settlements. The proportion of urban population to the total population of the Nenetsk region is $70 \%$, which is quite close to the average of Russia (74\%) [3]. The main part of the population is concentrated in the city of Naryan-Mar, and most of the settlements are concentrated around Naryan-Mar.

Nenetsk region relates to the Far North. The climate is sub-arctic, in the far north rolling in the Arctic: in the northeast the average January temperature is $-12^{\circ} \mathrm{C}$ and in the south-west $-22^{\circ} \mathrm{C}$, in the north the average July temperature is $+6^{\circ} \mathrm{C}$ and $+13^{\circ} \mathrm{C}$ in the south. Rainfall is approximately $350 \mathrm{~mm}$ per year. Furthermore the region is characterized by permafrost [1].

Nenetsk region is a rich region regarding the number of natural resources. The region has large reserves of oil and gas. There are 83 opened hydrocarbon deposits. The depth of hydrocarbons is relatively small, but the physicochemical properties are high, and as a consequence the profitability of most fields is high. The region has deposits of coal, manganese, nickel, copper, molybdenum, gold, diamonds, however, most of the fields are not fully explored. On the island of Vaigach lead-zinc and copper ores have been recently discovered [3].

Natural resources of the region determine the major industries: oil and gas, forestry and wood, and herding. The largest companies in the region, mainly related to oil and gas are "Surgutneftegaz", "Oil Company Rosneft", "Total Exploration and Development of Russia", "Polar Lights", "LUKOIL-North" ("LUKOIL-Severneftegas") [2].

To determine the specificity of the region it was compared with other regions of Russia on the basis of socio-economic indicators, using statistics from Rosstat [3]. After that, we analyzed the basic infrastructure sectors - electricity, transport and information and telecommunications.

Analysis of sectorial specialization of Nenetsk region shows the lack of diversification of the economy, the predominance of extractive industries and the region's dependence on market conditions of hydrocarbons.

Despite high incomes, a small part of the population pursues higher education. Per 1000 population only 159 have higher education. It's ranked 78 out of 83 in Russia.

Analysis of the infrastructure of the transport industry in the region shows that the only city in the region - Naryan-Mar - is not connected to other cities by permanent highway or railway. The main method of transportation is aviation. Also for other settlements in the region, transportation is carried out mainly by helicopters and aircraft and in some villages can be reached using by rivers.

Regarding the power sector, the Nenetsk region has only one major power plant - Naryan-Mar gas turbine power plant. The total length of power lines is only 253 kilometers. The region produces electricity less than it consumes [4].

The analysis shows the bad state of the housing sector in the region. The region at the end of 2012 had almost no dilapidated dwellings, but only $47.5 \%$ of the total living area is equipped with a water supply. Only $36.8 \%$ of premises are 
equipped with hot water, and $37.9 \%$ with sanitation. Only the indicator for home heating equipment is high: $95.2 \%$, which is extremely necessary to survive in the harsh climatic conditions $[2,5]$.

Information and communication industry is underdeveloped, despite the fact that $70 \%$ of households have a personal computer, and $47.6 \%$ have access to the Internet. Mobile communications in the region practically do not work.

According to the portal "Innovation in Russia", Nenetsk region is in last place in the ranking of innovation [6].

Due to dominance of extractive industries and lack of diversification of economic activities the region relies on the supply of goods from other regions. However the delivery of goods is difficult because of bad conditions of transport infrastructure.

A small proportion of the population with higher education and thus no skilled labor creates a barrier to innovation and lack of efficiency.

The analysis shows to the following main problems of the Nenetsk region: lack of roads, railroads, low electricity and communication services.

The program of Russia's social and economic development of the Arctic Region highlights the strategic priorities of the Nenetsk region: outpacing economic growth, economic diversification, innovation and transformation of human capital in economic growth, the creation of modern infrastructure and effective public administration system [7, 8].

\section{Methodological basis for the analysis of sustainable development}

Sustainable development of a region in general is the process of positive and uniform change of the space in which people live and work. The relationship of space areas should be coordinated with each other. Areas of spaces in which people live and work can be characterized as follows: the natural area of production and industrial infrastructure, social infrastructure, ecological systems, and social institutions. Development of all areas of life and space of human activity is significantly influenced by scientific and technological progress. Scientific and technological progress is a driving factor in the changes in all spheres of the spaces in which people live and work.

This definition of sustainable development is considered in terms of the following components: economic, social, and environmental. The economic component of sustainable development is based on the concept of optimal use of limited resources and use of environmentally friendly technologies. It is assumed that the material-technology should be used, including the extraction and processing of raw materials. The social component is aimed at sustainable development of social infrastructure. From an environmental point of view sustainable development must ensure the integrity of ecosystems (ecosystem is a biological system consisting of a community of living organisms and their habitats).

Based on the thoughts mentioned above, it is possible to give a broader definition of sustainable development in a region. 
Sustainable development of a region in a broad sense is a process that is characterized by the following conditions:

a) Uniform change of the natural environment, production of material goods, industrial infrastructure, social infrastructure, ecological systems, and social institutions surrounding the people in the region.

b) Changing the scope of the space surrounding a person is considered in terms of economic, social and environmental pillars.

c) The main reason for changing the scope of the space is scientific and technological progress.

Methodological basis for the analysis of sustainable development of a region is the theory of spatial economics and the theory of modeling. Spatial economic analysis is a modern scientific discipline, but the formation of theories, which gave impetus to its development, goes back to the time of Adam Smith and David Ricardo.

Significant contribution to the scientific categories of spatial economics are made by Weber [24], Tyunen [25], Kasper [13], Korenik and Miszczak [14], Krugman [11], Hoover [12], Duranton [10], Minakir [16], Launhardt [26], Kristallera [27].

\section{Modeling the development of the region}

\subsection{Theoretical model and its characteristics}

As a theoretical model an autoregressive distributed lags model (ADL-model) is selected. Thereby the current values depend on the number of past values of the series and on current and past values of other time series.

The model is generalized to the case of several exogenous variables. In general, we can assume that all the exogenous variables are included in the model with the same number of lags, perhaps with some exception.

The ADL-model has the following form:

$$
y_{t}=a_{0}+\sum_{i=1}^{n} a_{i} y_{t-i}+\sum_{j=0}^{q_{1}} b_{j} x_{t-i}^{1}+\ldots+\sum_{j=0}^{q_{k}} b_{j} x_{t-i}^{k}+E_{t}
$$

where $\mathrm{k}$ - number of exogenous variables; $q$ - number of lags; $n$ - the depth of the variable delays; $E_{t}$ - residues forming white noise process.

This model suggests that if at a certain time $t$ the independent variable $x$ changes, then this change will affect the value of the variable $y$ at the next time period.

\subsection{Data}

Working with the data consisted of two stages. After we selected endogenous and exogenous variables that correspond to the analyzed processes and reflect the essence of the problem the data was collected. Data was collected for the period from 2004 to 2013 containing the values of endogenous and exogenous variables for the corresponding year. The data was retrieved from the following 
sources: Federal State Statistics Service (electronic resource) http://www.gks.ru/ [3].

The following endogenous variables have been selected:

$y_{t}^{1}$ - Proportion of the region's GRP in year $\mathrm{t}$.

$y_{t}^{2}$ - Proportion of exports of the region in the year $\mathrm{t}$.

$y_{t}^{3}-$ Wage level in the region in year $\mathrm{t}$.

$y_{t}^{4}-$ Emissions of air pollutants from stationary sources in the region in year $\mathrm{t}$.

$y_{t}^{5}$ - Proportion of the region's volume of products shipped in year $\mathrm{t}$.

$y_{t}^{6}-$ Level of the development of infrastructure industries in the region in year $\mathrm{t}$.

The following exogenous variables have been selected:

$x_{t}^{1}-$ Volume of supplied innovation related products and services in year $\mathrm{t}$.

$x_{t}^{2}-$ Labor productivity in year $\mathrm{t}$.

$x_{t}^{3}-$ Costs of technological innovation in year $\mathrm{t}$.

$x_{t}^{4}-$ Ratio of physicians per 10,000 people in year $\mathrm{t}$.

$x_{t}^{5}-$ Growth rate of labor productivity in year $\mathrm{t}$.

$x_{t}^{6}-$ Level of the development of manufacturing industries in year $\mathrm{t}$.

$x_{t}^{7}-$ Proportion of social infrastructure sector in the region in year $\mathrm{t}$.

$x_{t}^{8}-$ Energy costs in year $\mathrm{t}$.

$x_{t}^{9}-$ Average permanent population in year $\mathrm{t}$.

\subsection{Methods of empirical testing model}

Empirical test of the model consisted of the following steps. The choice of exogenous variables that are closely related to endogenous variable was made using correlation analysis. Degree of interdependence between pairs of variables was determined based on the values of correlation coefficients and their significance level. Autocorrelation analysis of the time series of endogenous variable and time series of exogenous variables was conducted in order to identify lags having the greatest impact on the resulting variable. To determine the correlation of variables being analyzed a correlation matrix of variables has been used. The significance was assessed using the criteria of the standard error and Q-Box-Pearson criterion. For a pair of variables with a correlation coefficient greater than 0.8 one variable was removed from further analysis. To check the properties of stationary time series Dickey-Fuller test, i.e. unit root test has been used.

The system of equations is created in the form of structural shape model. A structural form model is an econometric model in which the equations are estimated in the form of stochastic correlations between current and lag values of variables in the model. Necessary and sufficient conditions of identifiable 
equations in the structural form model can be defined as follows. A necessary condition for identifiable equation:

$$
\begin{aligned}
& D+1=N-\text { Equation is identified; } \\
& D+1<N-\text { Unidentified equation; } \\
& D+1>N-\text { Over identified equation, }
\end{aligned}
$$

where $N$ is the number of endogenous variables in the $\mathrm{i}$-th equation of the system and $D$ is the number of exogenous variables in the system which are not included in the equation of interest.

A sufficient condition for identification of an equation requires that a matrix whose determinant is not zero, and the rank of it is not less than the number of endogenous variables in the system less one can obtained through coefficients of the missing variables (endogenous and exogenous) in one equation but acting as variables in other equations of the system.

The following concerns have been considered by selecting the method for estimating the parameters of the structural model. If the model is identifiable we used the method of indirect ordinary least squares (OLS). If the model was over identified we used the method of two-step OLS. For over identified equation the theoretical values of the endogenous variables have been estimated. After substituting them for the actual values conventional OLS has been used on the improved structural form of over identified equations.

Calculation of the coefficients in the structural form and the transition from a structural form model to the reduced form model is characterized by the following factors. The number of equations in reduced form is the number of endogenous variables in the model. In each equation of the reduced form the endogenous variable is expressed through all predefined variables in the model. Assessment of the adequacy of equations in the reduced form model was performed based on Fisher's F-test and the coefficients of the reduced form have been estimated using OLS.

\section{Empirical testing model}

Choosing exogenous and endogenous variables allowed us to construct a system of equations in the following structural form model:

$$
\left\{\begin{array}{l}
y_{t}^{1}=a_{1} x_{t}^{2}+a_{2} x_{t}^{6}+a_{3} x_{t}^{7}+a_{4} y_{t-1}^{3}+a_{5} y_{t}^{5}+a_{0} \\
y_{t}^{2}=b_{1} x_{t-1}^{7}+b_{2} x_{t-1}^{8}+b_{3} y_{t-1}^{1}+b_{4} y_{t-1}^{5}+b_{0} \\
y_{t}^{3}=c_{1} x_{t-1}^{2}+c_{2} x_{t-1}^{6}+c_{3} x_{t-1}^{8}+c_{4} x_{t-1}^{9}+c_{5} y_{t-1}^{3}+c_{0} \\
y_{t}^{4}=d_{1} x_{t}^{6}+d_{0} \\
y_{t}^{5}=e_{1} x_{t}^{6}+e_{2} x_{t}^{7}+e_{3} x_{t}^{8}+e_{0} \\
y_{t}^{6}=g_{1} x_{t}^{7}+g_{2} y_{t}^{1}+g_{0}
\end{array}\right\}
$$

where $a_{0}, \ldots a_{5}, b_{0}, \ldots b_{4}, c_{0}, \ldots c_{5}, d_{0}, d_{1}, e_{0}, \ldots e_{3}, g_{0}, \ldots g_{2}$ are coefficients of the structural form model. 
The structural forms model has been transformed into an improved structural form:

$$
\left\{\begin{array}{l}
y_{t}^{1}=a_{1} x_{t}^{2}+a_{2} x_{t}^{6}+a_{3} x_{t}^{7}+a_{4} y_{t-1}^{3}+a_{5}\left(e_{1} x_{t}^{6}+e_{2} x_{t}^{7}+e_{3} x_{t}^{8}+e_{0}\right)+a_{0} \\
y_{t}^{2}=b_{1} x_{t-1}^{7}+b_{2} x_{t-1}^{8}+b_{3} y_{t-1}^{1}+b_{4} y_{t-1}^{5}+b_{0} \\
y_{t}^{3}=c_{1} x_{t-1}^{2}+c_{2} x_{t-1}^{6}+c_{3} x_{t-1}^{8}+c_{4} x_{t-1}^{9}+c_{5} y_{t-1}^{3}+c_{0} \\
y_{t}^{4}=d_{1} x_{t}^{6}+d_{0} \\
y_{t}^{5}=e_{1} x_{t}^{6}+e_{2} x_{t}^{7}+e_{3} x_{t}^{8}+e_{0} \\
y_{t}^{6}=g_{1} x_{t}^{7}+g_{2}\left[a_{1} x_{t}^{2}+a_{2} x_{t}^{6}+a_{3} x_{t}^{7}+a_{4} y_{t-1}^{3}+a_{5}\left(e_{1} x_{t}^{6}+e_{2} x_{t}^{7}+e_{3} x_{t}^{8}+e_{0}\right)+a_{0}\right]+g_{0}
\end{array}\right\}
$$

For each equation of the improved structural form the reliability of the regression equation has been evaluated based on the F-Fisher criterion. The coefficients have been calculated using OLS, and the reliability of coefficient was verified using the standard t-test.

For $y_{t}^{1}$ :

Critical- $F=9.01<F=32.274$. Thus the regression equation is statistically significant at the level $\alpha=0.05$ and has the form:

$$
\begin{aligned}
y_{t}^{1}= & (3,287 E-0,10) x_{t}^{2}-0,013 x_{t}^{6}-0,054 x_{t}^{7}+(-7,913 E-0,08) y_{t-1}^{3} \\
& +(4,607 E-0,09) x_{t}^{8}+0,004
\end{aligned}
$$

For $y_{t}^{2}$ :

Critical- $F=6.39<F=7.689$. Thus the regression equation is statistically significant at the level $\alpha=0.05$ and has the form:

$$
y_{t}^{2}=0,368 x_{t-1}^{7}+(1,074 E-0,09) x_{t-1}^{8}+5,781 y_{t-1}^{1}-0,994 y_{t-1}^{5}-0,022
$$

For $y_{t}^{3}$ :

Critical- $F=9.01<F=134$. Thus the regression equation is statistically significant at the level $\alpha=0.05$ and has the form:

$$
\begin{aligned}
y_{t}^{3}= & 0,002 x_{t-1}^{2}+1020194,030 x_{t-1}^{6}-0,028 x_{t-1}^{8}-2,137 x_{t-1}^{9} \\
& +0,198 y_{t-1}^{3}+162825,498
\end{aligned}
$$

For $y_{t}^{4}$ :

Critical- $F=5.59<F=6.335$. Thus the regression equation is statistically significant at the level $\alpha=0.05$ and has the form:

$$
y_{t}^{4}=-78515,947 x_{t}^{6}+313,464
$$

For $y_{t}^{5}$ :

Critical- $F=5.41<F=11.882$. Thus the regression equation is statistically significant at the level $\alpha=0.05$ and has the form: 


$$
y_{t}^{5}=-0,131 x_{t}^{6}-0,131 x_{t}^{7}+(2,722 E-0,09) x_{t}^{8}+0,007
$$

For $y_{t}^{6}$ :

Critical- $F=9.01<F=35.274$. Thus the regression equation is statistically significant at the level $\alpha=0.05$ and has the form:

$$
\begin{aligned}
y_{t}^{6}= & (-3,919 E-0,08) x_{t}^{2}-138,472 x_{t}^{6}+17,397 x_{t}^{7} \\
& +(-5,130 E-0,07) x_{t}^{8}+(8,183 E-0,06) y_{t-1}^{3}+0,306
\end{aligned}
$$

A necessary condition for the identification of the model was considered for each equation of the improved structural model. All six equations were over identified. In addition to that the sufficient condition for identification was also verified for all equations in the system. Because among the equations of the system all equations were over identified the model as a whole was also over identified and, therefore, to determine the parameters of the equations two-step OLS was used.

Using the improved structural form of the model for all over identified equations, theoretical values of the endogenous variables were calculated and substituted in the resulting system of equations of the initial values of exogenous variables. Furthermore theoretical values of the endogenous variables were substituted into the structural from model. The reliability of the regression equation was tested based on the F-Fisher criterion. The coefficients were calculated using OLS and tested with the standard t-test.

The final system of simultaneous econometric equations is as follows:

$$
\left\{\begin{array}{l}
y_{t}^{1}=(3,278 E-0,10) x_{t}^{2}+0,208 x_{t}^{6}+0,168 x_{t}^{7}+(-7,899 E-0,08) y_{t-1}^{3}+1,692 y_{t}^{5}-0,007 \\
y_{t}^{2}=0,369 x_{t-1}^{7}+(1,070 E-0,09) x_{t-1}^{8}+5,781 y_{t-1}^{1}-0,993 y_{t-1}^{5}-0,022 \\
y_{t}^{3}=0,002 x_{t-1}^{2}+1020104,516 x_{t-1}^{6}-0,028 x_{t-1}^{8}-2,137 x_{t-1}^{9}+0,198 y_{t-1}^{3}+162825,5 \\
y_{t}^{4}=-78516,125 x_{t}^{6}+313,466 \\
y_{t}^{5}=-0,131 x_{t}^{6}-0,132 x_{t}^{7}+(2,721 E-0,09) x_{t}^{8}+0,00 \\
y_{t}^{6}=4,226 x_{t}^{7}-65,294 y_{t}^{1}+0,399
\end{array}\right\}
$$

\section{Conclusion}

In this paper, the development of the Nenetsk region is being analyzed using concepts of spatial economics and the theory of modeling. Each area of sustainable development of a region is estimated by indicators that are either endogenous or exogenous variables in the model. For each endogenous parameter the model has its own exogenous parameters. Choosing exogenous and endogenous variables allows us to construct a system of equations in the structural forms.

Structural form of the model in some cases can be converted into an independent system of equations. In our case it was not possible to make the 
transformation and the model has been transformed into an improved structural form. This article shows solutions for the improved structural form.

The analysis and evaluation of the necessary and sufficient conditions for identification of the model showed that among the equations of the system there are no unidentifiable equations, all equations are over identifiable. On this basis, to determine the parameters of the equations a two-step OLS has been used and the system of econometric equations has been solved.

\section{Acknowledgement}

This paper is based on research carried out with the financial support of the grant of the Russian Scientific Foundation (Project No. 14-38-00009), St. Petersburg Polytechnic University.

\section{References}

[1] Administration Nenets Autonomous Area (an electronic resource) http://adm-nao.ru/.

[2] Regional portal of the Nenets Autonomous Area (an electronic resource) http://www .info83.ru/transport/paromnaryan-mar.

[3] Federal State Statistics Service (an electronic resource) http://www.gks.ru/

[4] System Operator of the Unified Energy System (an electronic resource) http://www.so-ups.ru/.

[5] Strategy of social and economic development of the Arkhangelsk region till 2030//the Government of the Arkhangelsk region (an electronic resource) http://www .dvinaland.ru/economy/strategy/.

[6] Innovations in Russia (an electronic resource) http://innovation .gov.ru/.

[7] Concept of Strategy of social and economic development of regions of the Russian Federation (an electronic resource) http://www.archipelag.ru/ agenda/povestka/evolution/strategy/.

[8] The order of the Government of the Russian Federation, 21.04.2014 N 366 about approval of a state program of the Russian Federation "Social and economic development of the Arctic zone of the Russian Federation for the period till 2020". 2014.

[9] Crosier S. Johann-Heinrich von Thünen: Balancing Land-Use Allocation with Transport Cost / Center for Spatially Integrated Social Science.

[10] Duranton G. Spatial Economics / The New Palgrave Dictionary of Economics. Second Edition. Eds. Steven N. Durlauf and Lawrence E. Blume. Palgrave Macmillan, 2008.

[11] Economic models of the Nobel laureate Paul Krugman / In the world of economy (an electronic resource) http://worldofeconomy.ru/.

[12] Hoover E.M. Spatial Economics: The Partial Equilibrium Approach International Encyclopedia of the Social Sciences (January 1968).

[13] Kasper W. Spatial Economics / The Concise Encyclopedia of Economics / Econlib (Электронный ресурc) http://www.econlib.org/. 
[14] Korenik S., Miszczak K. Region as a Fundamental Unit in Modern Spatial Economy / Spatial Economy and Self-governed Administration Wroclaw University of Economics / GeoScape 6(1-2). pp. 11-17. 2011.

[15] Krugman P. R. The Role of Geography in Development // International Regional Science Review. Vol. 22. № 2. pp. 142-161. 1999.

[16] Minakir P. A. Ekonomika and space (theses of reflections) / Spatial economics, pp. 4-26, No.1. 2005.

[17] Didenko N., Kunze K. Relationship between Energy Policies and Quality of Life in Russia. WIT Transactions on $5^{\text {th }}$ International Energy and Sustainability conference, 196. Vol 1. pp. 145-154. 2014.

[18] D. H. Meadows , J. M. Robinson. The Electronic Oracle: Computer Models and Social Decisions - May, 1985.

[19] Bernasovskaya L.I., Vectorov A.D., Kormanovskaya I.R. System approach to forecasting of a sustainable development of the region: Theory. Methodology. Practice. M. Sputnik, 2010.

[20] Granberg A.G. Fundamentals of regional economy / the Textbook for the student. Higher education institutions / A. G. Granberg. 3rd prod. M.: GU HSE, 2003.

[21] Merzlyakov V. F., Vinokurov A.A. Problems of a sustainable development of the region in modern economy//the Russian entrepreneurship. №4 (202). pp. 158-162. http://www.cremy.ru/articbs/ 19866/2012.

[22] Vasilyev A.S. Five-factorial model of sustainable social and economic development//Creative economy.№4 (64). pp. 3-9. 2012.

[23] Zang V. B. Sinergeticheskaya economy. M. p. 3351999.

[24] Weber, M. Economy and Society / Trans. with Germany. Under the scientific. ed. L.G Ioannina. M.: Publishing House of the HSE, 2010.

[25] Blaug M. The theory of marginal productivity Thünen // Economic thought in retrospect = Economic Theory in Retrospect. M.: Delo, 1994. pp. 299-302. XVII, 627 p. ISBN 5-86461-151-4.

[26] Curtis Eaton, B., and Lipsey, R.G., An Economic Theory of Central Places The Economic Journal, Vol. 92, No. 365. (Mar., 1982), pp. 56-72.

[27] Ursula Backhaus, An engineer's view of economics: Wilhelm Launhardt's contributions, Journal of Economic Studies, 08/2000; 27 (September): pp. $424-476$. 